\title{
BMJ open The ethics of unlinked anonymous testing of blood: views from in-depth interviews with key informants in four countries
}

\author{
Anthony S Kessel, ${ }^{1}$ Jessica Datta, ${ }^{2}$ Kaye Wellings, ${ }^{2}$ Sarah Perman ${ }^{3}$
}

To cite: Kessel AS, Datta J, Wellings $\mathrm{K}$, et al. The ethics of unlinked anonymous testing of blood: views from in-depth interviews with key informants in four countries BMJ Open 2012;2:e001427. doi:10.1136/bmjopen-2012001427

- Prepublication history for this paper are available online. To view these files please visit the journal online (http://dx.doi.org/10.1136/ bmjopen-2012-001427).

Received 28 May 2012 Revised 8 November 2012 Accepted 12 November 2012

This final article is available for use under the terms of the Creative Commons Attribution Non-Commercial 2.0 Licence; see http://bmjopen.bmj.com

${ }^{1}$ Department of Social and Environmental Health Research, London School of Hygiene and Tropical Medicine, London, UK ${ }^{2}$ London School of Hygiene and Tropical Medicine, London, UK

${ }^{3}$ Specialist Registrar in Public Health

\section{Correspondence to}

Professor Anthony S Kessel; anthony.kessel@Ishtm.ac.uk

\section{ABSTRACT}

Objectives: In this study we explore the ethical issues around unlinked anonymous testing (UAT) of blood, a method of seroprevalence surveillance for infectious diseases. Our study focused on UAT for HIV, although UAT can be used for other infectious diseases. The objectives of the research were to gain a better understanding of the views of key informants in countries adopting different UAT testing strategies, and to use the findings of the research to inform health policy.

Design: Qualitative study using in-depth interviews and ethical analysis.

Setting: Four countries using different strategies around UAT of blood for HIV (the UK, the USA, the Netherlands and Norway).

Participants: Twenty-three key informants in the four countries.

Results: Participants from the four countries have different views on UAT of blood, and the approaches and policies on UAT adopted by different countries have been historically and culturally determined. We use our findings to explore the relationship between public health policy and ethics, framing our discussion in relation to two important contemporary debates: informed consent for participation in medical and public health research; and the balance between the individual good and the public good.

Conclusions: Qualitative research and ethical analysis of UAT of blood in different countries has yielded important findings for consideration by policy makers. The policy of UAT of blood for HIV and other diseases in the UK needs reconsideration in the light of these findings.

\section{BACKGROUND}

Unlike voluntary testing for clinical purposes, unlinked anonymous testing (UAT) of blood is carried out in order to provide information about the prevalence of particular infectious diseases in a population. The use of UAT began in the late 1980s for HIV, and remains most commonly associated with this

\section{ARTICLE SUMMARY}

\section{Article focus}

- To gain a better understanding of historical and ethical issues around unlinked anonymous testing (UAT) of blood through the views of key informants in countries adopting different approaches to UAT.

- To use the findings of the research to explore the relationship between public health policy, context and ethics.

- To use the findings of the research to inform the development of health policy.

Key messages

- Different countries have adopted different policies around UAT for blood based on a range of historical, ethical, epidemiological and contextspecific considerations.

- It is important to intermittently review policy positions around UAT for blood, as the context and ethical dimensions may change with time.

- Ethical issues around UAT need consideration within broader contemporary debates in medical and public health ethics: the boundaries of informed consent in medical and public health research; and the balance between individual rights and public (health) interests.

Strengths and limitations of this study

- Interviews were with informants from countries representing a range of approaches to UAT of blood.

- Combination of social scientific qualitative research with ethical analysis and debate.

- Small number of informants interviewed in some countries.

infection, but can be applied to other infectious diseases such as hepatitis C. ${ }^{1}$ In this paper we use the term UAT synonymously with seroprevalence surveys, or seroprevalence surveillance.

The principles behind UAT can be explained with reference to the approach used in the UK for HIV. Leftover blood from 
samples taken for diagnostic or routine screening purposes is made anonymous, irreversibly unlinked from the source, and then tested for HIV. ${ }^{3}$ This means that individuals whose blood tests are positive for HIV cannot be contacted or informed. The data derived from UAT are then used for monitoring purposes and also to inform the planning and evaluation of health services and health promotion activities.

Historically, UAT has developed in different ways in different settings, yet exploration of the moral dimensions of such developments has been relatively limited. ${ }^{4-6}$ Further, dominant attention given to individual rights and autonomy-in the health and healthcare contextmake it an appropriate time to reassess moral considerations around UAT. A brief summary of developments in UAT in the four countries used in our study is provided as a necessary introduction to the research project.

\section{History of UAT in different countries}

A national seroprevalence surveillance programme using UAT to estimate the prevalence of HIV has been in place in the UK since $1990 .{ }^{1}$ The programme was first developed in response to concerns about the spread of HIV during the $1980 \mathrm{~s}^{7}$ and, despite early opposition, the methodology eventually gained political support. ${ }^{8}$ The programme was funded initially as a pilot project by the Medical Research Council, and has since been funded by the department of health. ${ }^{\mathrm{i}, \mathrm{ii}}$ The programme currently uses data collected from three ongoing surveys (newborn babies, (maternal antibodies), users of genitourinary medicine (GUM) clinics and intravenous drug users (saliva)) to measure the proportion of individuals within the general population, and within subgroups of the population, infected with HIV. Since the programme's inception, around 10 million blood samples have been tested in this way. ${ }^{9}$

A system of 'prior notification' operates in locations where testing goes on, involving the display of leaflets or posters explaining that blood may be tested anonymously. Consent to participation is implicit rather than explicit; provision is made to opt-out of testing, although this naturally depends on awareness. ${ }^{9} 10$

In the USA, UAT was extensively used in the late 1980s and early 1990s using discarded blood samples. The largest survey was national and used newborn heel prick tests. Other UAT surveys focused on population groups, for instance a survey of young people volunteering for job corps, although these were regional or local. In contrast to the UK the prior notification system, with the

\footnotetext{
${ }^{\mathrm{i}}$ The England and Wales programme is currently managed by the Health Protection Agency (HPA) and the Institute of Child Health, University of London. The programme was previously managed by the Communicable Disease Surveillance Centre, part of the Public Health Laboratory Service, which was subsumed into the Health Protection Agency in 2005.

ii Health Protection Scotland (HPS) co-ordinates data collection in Scotland.
}

opportunity to opt-out, was not used. UAT essentially stopped in the USA in 1996, as evidence emerged in relation to reducing vertical transmission of the HIV virus from a pregnant mother to the fetus through the use of antiviral medicine. ${ }^{11}$ The interplay at the time of clinical, social and political factors was complex. ${ }^{12}$

The main method for HIV surveillance in the Netherlands is named voluntary testing rather than UAT (these are 'opt-out' programmes, such as the antenatal testing programme and the testing of users of STI clinics, as well as the extensive 'opt-in' testing carried out by general practitioners). The UAT that does occur in the Netherlands is carried out using blood samples from intravenous drug users (IDUs) and saliva samples from other groups. Unlike the UK or the USA, informed consent is required from those surveyed by UAT, either verbal or more recently, written consent. From 2002 to 2006, other high-risk groups have been included in UAT research surveys in the Netherlands (eg, migrants from the Cape Verde islands, Surinam and the Netherlands Antilles, as well as commercial sex workers), because of concerns of a higher proportion of undiagnosed HIV in such groups, who were also felt to be accessing health services less than others.

In Norway, public health efforts have focused on diagnosing all those infected, as it was thought (certainly in earlier stages) that those who were diagnosed would be less likely than those undiagnosed to transmit infection to others. Mandatory named AIDS reporting was introduced in Norway in 1983 and mandatory anonymous HIV case reporting in 1986, both including cases diagnosed before those dates. ${ }^{13}$ The Norwegian approach has therefore centred on individual testing and clinician reporting, and UAT has not been deemed epidemiologically necessary and has never been undertaken.

\section{AIMS AND OBJECTIVES OF THE RESEARCH STUDY}

The ESRC-funded project had three components: a questionnaire survey of 471 patients attending two innerurban GUM clinics in two English cities, exploring their views of and attitudes towards, UAT; ${ }^{14}$ qualitative in-depth interviews with a subsample (20) of these patients; and in-depth interviews with key informants in four countries chosen to represent different approaches towards sero-surveillance for HIV. In this paper, we present findings from this third component, the qualitative interviews with key informants.

The overarching aim of this component of the research study was to use the subject of UAT, and our findings, to explore the relationship between public health policy, context and ethics. There were two more specific objectives of the research. The first was to gain a better understanding of how UAT has developed in different settings over time, with particular attention to the ethical considerations. The second was to use UAT as an instrument to gain empirical understanding of the ethical tensions between surveillance and patients' 
rights, and to explore how these tensions may have developed and been handled in different contexts.

\section{METHODS}

Four countries were selected purposively to participate in this study component (the key informant interviews), based on their representing a range of approaches or positions taken, with regard to UAT: the UK (specifically England), the USA, the Netherlands and Norway. Purposive sampling was used to select the key informants from these countries, informed by the following criteria: range of stakeholder perspectives (eg, epidemiology, clinical, public health policy, charity or pressure group and academia (public health or medical ethics)); involvement in UAT and with appropriate knowledge or expertise, historically and/or current; existing links with the research team or advisory group members; and practical issues (eg, availability and likelihood of participation). A pragmatic approach meant that more informants were interviewed in the UK than in the other countries.

A topic guide was developed that allowed for a semistructured interview. Elements within the topic guide included: introduction and background to the purpose and nature of the interview (prior information had been provided); knowledge and views on UAT of blood (and national programme as appropriate), including advantages and disadvantages; ethical considerations including consent, prior notification, confidentiality, anonymity, individual rights/liberties, social responsibilities and any changes in ethical position over time; the value to public health of different surveillance methods; blood as a tissue; legal considerations; and any other relevant issues the respondent wished to discuss. The topic guide was initially tailored for the different countries based on our own understanding, but then applied flexibly during the interview.

A researcher, with a background and skills in qualitative interviewing, was employed for the duration of the project, and undertook all the interviews. Interviews were carried out, in English, either face-to-face or by telephone between January and September 2008. All non-UK informants spoke good English, without evidence to the research team of any obvious language barrier issues. Interviews were recorded (except for two, when notes were taken: the first due to unsuitable location and the second to mechanical failure) with the participant's permission, and transcribed verbatim. Interviews lasted between $20 \mathrm{~min}$ and $1 \mathrm{~h}$, the length directed by the contributions of the informants. In total 21 interviews were completed with 23 respondents (two interviews were with two respondents together). Of these, 12 were with the UK respondents (three clinicians in GUM/HIV; one person working in government health policy; two HIV epidemiologists; two ethics academics; two charity representatives (MedFash, Terence Higgins Trust); one person working at the British Medical Association; one editor of a medical journal), four with respondents in the USA (one health policy academic; one academic in health law; one academic in public health and one epidemiologist), three with respondents from the Netherlands (two epidemiologists and one academic in medical ethics) and four with respondents in Norway (one epidemiologist and three academics in medical ethics-one of whom is also a hospital clinician). There were three interview refusals, all in the UK. ${ }^{\text {iii }}$

Two researchers (primary researcher, JD, and a second researcher, SP) coded the interview data using a thematic content analysis approach, looking for emergent themes (open coding in the context of the aims and objectives of the research). There were no discrepancies between the two researchers that required further discussion and consensus. The content was analysed for a description of UAT developments in the country concerned, the context in which UAT may have changed, ethical tensions in UAT between surveillance and human rights and broader connections between UAT and public health policy. Inevitably some of the themes interlink with each other (eg, 'value of UAT' and 'ethical issues'). Coding frames and analyses were shared with the wider research team. In a relatively small study of this kind it is not possible to indicate definitively if data saturation was reached, and the focus was on the emergent themes.

Interview data pertaining to the history and factual state of sero-surveillance in different countries were triangulated, for the purpose of the discussion section, with literature sources. It was not appropriate to triangulate informants' views on sero-surveillance; as such data were treated as informants' opinions and perceptions.

\section{RESULTS}

The results, which represent the views and perceptions of informants, are presented by themes and by country. The labels describe the themes that emerged, in the context of informants' awareness of the aims and objectives of the study.

\section{Value of UAT}

The UK

The programme is largely seen by respondents as indispensable in providing an unbiased measure of HIV prevalence and risk factors in the UK population. The most important outcome from the surveys has been information on undiagnosed HIV infection which, respondents suggested, has led to changes in policy on named testing; for example, HIV testing in pregnant women has changed from opt-in to opt-out, and sexual health clinics have moved from targeted to universal voluntary testing. The neonatal dried blood spot survey is used as a check on the performance of local antenatal screening. The public health rationale for the

\footnotetext{
${ }^{\text {iii }}$ Those chosen had particular involvement or interest in UAT and ethics, but further details cannot be provided to maintain their confidentiality.
} 
programme has not changed since 1990, and respondents cited the continuing high infection rate, particularly among men who have sex with men, as justification:

There was far more feeling of a public health emergency (then) than there is today, although you could argue ... that it's actually much worse today because of where we see the disease. (UK 4)

Several respondents suggested that a review of UAT would be timely, including consideration of extending the surveys to other healthcare settings and other diseases. UK 6 discussed how advances in HIV testing, including self-testing, might alter the questions asked by the programme. Some suggested that if named testing was normalised, there would be less need for anonymous testing.

A particular theme was whether the British public has a duty to participate in public health monitoring, possibly as part-and-parcel of receiving the benefits of a National Health Service (NHS):

There is a very good case for really exploring with the public, and then pushing very hard to get public agreement, that in general terms that sort of tissue, extra bits of tissue or blood, should be available for use. (UK 4)

\section{The USA}

According to one respondent, the surveillance programme was valuable in terms of planning, resource allocation, advocacy and interventions to prevent transmission. The heel prick survey provided accurate national data on prevalence in childbearing women and was seen as extremely valuable, with nothing since that has given as accurate a picture of national prevalence (USA 2).

However, given the questionable ethics of UAT (see later), as well as the resultant lack of good-quality prevalence data, USA 3 argued that enough became known about prevalence to target the most vulnerable groups for health promotion.

And how much more detail do you want from that, so what would you do differently if you knew that in the next level of detail. (USA 3)

\section{The Netherlands}

Unlinked anonymous surveys have been used in the Netherlands to measure HIV prevalence among highrisk populations, but with informed consent (verbal or written). The populations surveyed by UAT have changed over time. IDUs have been surveyed bi-annually since 1994 in different cities in the Netherlands, and are recruited via methadone care; sex workers and migrant groups have also been subject to UAT surveys.

There are two reasons, indicated by respondents, why UAT in the Netherlands has been of limited value. First, the uptake of voluntary testing is generally high in the Netherlands, meaning the quality of that data are generally good. And second, UAT has only been deemed ethically permissible in the Netherlands with informed consent, making large-scale UAT surveys impracticable, so restricting UAT to specific population groups and/or the research context.

\section{Norway}

The unknown, undiagnosed segment of the population is known as the 'dark figure(s)' in Norwegian, although neither the 'dark figure' nor the number of cases of HIV has been perceived as significant issues in Norway. Uptake of voluntary testing for HIV was described as very high in IDUs and antenatal clinic users, meaning that UAT has never been perceived as to be of value epidemiologically. The system of surveillance for HIV in Norway instead covers all diagnosed cases (ie, not undiagnosed cases as with UAT), and was reported as being simple, inexpensive and capable of providing a representative and timely overview that guides prevention, while respecting confidentiality and adhering to ethical principles.

\section{Quality and nature of data}

The UK

The epidemiological data yielded from UAT are considered by respondents to be of unrivalled quality internationally. It was suggested, however, that the apparent high number of undiagnosed HIV infections from UAT surveys might be inflated by double-counting:

You can quite understand that if you've got gonorrhoea and you've been told by your doctor not to have unsafe sex, you might well decide to go to a different clinic to have your gonorrhoea treated. (UK 1)

Others defended the statistics and argued that they were explained by a resurgence of high-risk behaviour, particularly among gay men. UK 1 argued that people who refuse a named test and who are subsequently found to be HIV positive through UAT are likely to be people who know that they are positive.

\section{The USA}

There was little comment from the USA interviewees about the quality of UAT data, since UAT surveys stopped in 1996. However, a theme that emerged in relation to UAT data was around the difference between research and surveillance.

The fact that there is no 'right' to healthcare in the USA was felt to have an effect on people's views on surveillance-in other words, the 'disconnect' between healthcare provision (not available to all) and surveillance (done to all) (USA 1). The differences between surveillance, research and practice, with perhaps different ethical standards required for each, emerged as a theme from the interviews (USA 4).

One point of view was that surveillance (because it is named and part of routine care) is part of clinical care rather than purely research (USA 2). However, while 
some of the surveillance undertakings at the state level in the USA were considered to be practice, at the level of CDC they were treated as research (USA 1). The same respondent commented that cancer sufferers advocated in favour of surveillance for the purposes of research on the disease, since "they were willing to trade privacy and consent for a good which was surveillance that they saw as serving their interests."

\section{Norway and the Netherlands}

There were no comments from Norway respondents about the quality of UAT data since such surveys are not carried out in Norway, in part because of the good quality of data on HIV and AIDS from other sources.

Two respondents from the Netherlands judged that large-scale UAT programmes were not necessary because named HIV testing is widespread. The quality of information obtained from named testing was felt to be robust and could be used to model estimates of HIV prevalence in the population. Coverage of pregnant women is very high and this group is considered as a valid proxy for the heterosexual population. Named HIV testing among users of STI clinics was also presented as being a valid method for estimating prevalence. It was argued that, as long as the uptake of named testing by pregnant women and STI clinic users remains high (above 90\%) then a national programme of UAT was not thought to be necessary. However, notwithstanding the above point it was acknowledged that current methods of surveillance do not allow undiagnosed HIV infection to be measured accurately.

\section{Ethical issues}

The UK

Respondents felt that, on balance, no harm was caused by the programme. A recurrent argument for this was that, in settings where anonymous testing takes place, people are offered a named HIV test:

I think the ethics are not in fact, are not a problem because everybody is now very strongly advised to have a test and therefore the residual rump who don't have a test, it's important to know what their rate of HIV positivity is. (UK 1)

Some respondents, however, said there would be ethical concerns if people in these settings were not routinely offered a named test. Several respondents considered the ethics of UAT to be relatively unimportant, for instance in the context of more significant health-related problems in Africa:

There are these enormous ethical, real ethical issues, and to me, this one ... I just can't understand why one should put so much emphasis on it. (UK 9)

The UK 11 suggested that the question of ownership of the sample was relevant, but that this could be argued both ways:
Is it yours or is it somebody else's? ... If it's waste that's going to be chucked away then why shouldn't people use it if they find it useful? On the other hand, 'I gave permission for this test for my own benefit and I didn't give you permission to do things to help others.'

There was a universal agreement that changing to a system of informed consent would damage the programme. There was a fear that introducing information about UAT into a clinical consultation could confuse patients. Patients might think they were getting a named test:

You would lose someone's confidence and trust because they might not understand the words or the reason behind why we're doing it, and they would think that you could get back to them and you did know. (UK 12)

Other respondents argued that it would reduce time for discussing important clinical matters:

When the midwife turns up, does she pull out a leaflet and say by the way, I'm putting this beside you here? ... it would be a perversion of the consultation to divert it into discussing this... (UK 5)

Further concerns were that a system of informed consent would increase refusals and lead to bias in the surveys, and also the time and cost of gaining consent from patients:

You know we've got 10 minutes appointments. It could take you 5 minutes, half of your time just to explain what this is all about. So doing it in a consultation is not realistic. (UK 3)

The respondent suggested that a system of clinic selfregistration, using computers, could be used to explain anonymous testing.

All the respondents thought that prior notification was the right theoretical approach. However, some were concerned that, in practice, it might not be working:

It's a reasonable thing in practical terms provided people are informed. So ... if people don't know about their option for opting out and their option for finding out then the system hasn't been working. (UK 11)

Some suggested that the approach needed to be more 'active' with information displayed visibly on clinic walls or in leaflets given out to each patient. One clinician, however, expressed his discomfort with his role in the programme. He described filling out the form for UAT blood testing in front of the patient, without explaining what he was doing, and sometimes after the patient had declined a named HIV test:

You're doing something that sort of seems slightly underhand ... you're not explaining it to the patient. Yeah, I'm not comfortable with that, I think one wants to be, to 
communicate well and to be as open as possible with patients and that's slightly in conflict with that. (UK 3)

\section{The USA}

Consent was not deemed necessary initially in the USA for participation in UAT as patients had consented to the blood being collected in the first place, and this was seen as adequate. The USA 1 suggested that surveillance is a public good, meaning there are strong reasons for making it a universal obligation on citizens-and that notification that surveillance is occurring is different from asking for consent.

The blood spot survey continued until the publication of the first trials showing that vertical transmission of HIV could be dramatically reduced by treating mothers. When it became clear that infected women could be offered treatment, and therefore should know their HIV status, "it became impossible for the US Centre for Communicable Disease Control and Prevention (CDC) to continue that programme and it was dropped in the early 1990s along with all the other ones" (USA 3). It had become difficult to reconcile public health benefits of UAT with individual rights. If CDC had not voluntarily withdrawn funding from UAT, the same respondent indicated that it was likely that Congress would have mandated cessation, as there was a strong coalition in favour of this.

A related legal issue was brought by USA 4 , in that public health surveillance appears to go against 'fundamental legal principles' in the USA, and constitutional scholars are shocked when they hear what is done.

Once you begin to argue that the government can take your personally identifiable information for any reason it finds useful without your consent you've opened up and blown a hole in much of the fundamental legal principles in the country. (USA 4)

The Tuskegee episode (a study between 1932 and 1972 in Alabama in which black syphilitic Americans were not given treatment although thought they were) was mentioned by USA 1 as a reason for USA citizens, particularly Afro-Americans, to be suspicious of surveillance practices. In the context of opposition to named case reporting and a consequent lack of trust in surveillance, USA 3 argued that there are probably cultural dimensions to issues such as consent, and the acceptability of particular interventions may vary from country to country.

It (UAT) became more of a civil rights issue than a gay specific one. It was, the government knows something that you don't and the attitude in the States, at least at the time, towards the government was much less trusting than in this country (ie, UK). People did not assume and still don't assume that the government necessarily is looking out for your well being. And I think there's a much more paranoid attitude towards the government than there is in this country. (USA 3)
Related to these cultural dimensions, a particular ethical concern was that the USA (and, in particular, CDC) supports UAT in developing countries, with the inherent contradiction that it has been rejected in the USA.

It seems to me the CDC can't at the one time say it's unethical to do it in the US and say it's ethical to do it abroad. Different public agencies may come to different decisions, but the same agency it seems to me should be bound by some rule of consistency. (USA 1)

The USA 2 felt very strongly that arrangements for UAT in developing countries are not ethical where pregnant women do not have the opportunity to have a named test, counselling and treatment.

\section{The Netherlands}

The respondents felt that more extensive UAT surveys would produce more accurate information for public health surveillance. However, inter-linked practical and ethical doubts about UAT were presented. One concern was that UAT might deter high-risk groups from seeking testing and treatment. Another concern was that, if UAT focused only on high-risk groups, such groups would risk being stigmatised. It was suggested that reporting of findings from UAT surveys of high risk groups would need to be carried out sensitively.

A particular issue was consent and maintaining trust with patients. One interviewee expressed that staff in HIV treatment centres and STI clinics demand a more stringent consent process than required by the research ethics committees in the Netherlands in order to promote trust among patients.

\section{Norway}

A UAT system was never thought relevant, necessary or appropriate for Norway. In Norway it is not legal to test or analyse blood or biological material for infectious diseases for non-diagnostic purposes without consent unless the purpose is surveillance of an 'epidemic'. One respondent felt this displayed a 'moral grey zone', as the law hinges on the definition of 'epidemic' (Norway 1).

There is very little concern or awareness in Norway about ethical issues around UAT. However, there is a general willingness to provide information for public health purposes in Norway and people are used to being surveyed. It was reported that many Norwegians have given blood to the Biobank, and give broad consent for their tissue/blood to be used for a wide range of research. A respondent indicated that many are willing to waive their consent in Norway because 'there is significant trust' in the healthcare system. However, another respondent expressed that there was a possible danger that UAT blood could be used to identify someone via the Home Office DNA database, and that researchers might be forced to share information under a court order (the respondent mentioned that the 
murderer of the Swedish politician Anna Lindh in 2003 was convicted on the basis of a match with DNA held in the national biobank).

One respondent suggested that informed consent could be different in different contexts. In a country like Norway, with low prevalence and easy access to healthcare, the current surveillance system (non-UAT) was described as acceptable and functioning well. However, in a country in Africa (where this respondent was carrying out research), with a high rate of HIV positive pregnant women and a low rate of testing, routine testing with opt-out consent procedures would be morally acceptable.

\section{DISCUSSION}

Since its inception, UAT has been a subject of epidemiological, ethical and policy debate. ${ }^{15-17}$ In this paper we have presented the results of qualitative interviews with key informants in four countries pragmatically selected because they represent a range of approaches to UAT. ${ }^{18}$ A total of 23 respondents were interviewed, differentially distributed between countries: 12 in the UK, 4 in the USA, 4 in Norway and 3 in the Netherlands.

There were limitations to the research: more key informants were interviewed in some countries than others; some interviews were face-to-face whereas others were by telephone; and two of the interviews relied on notes rather than recordings for later analysis. ${ }^{18-20}$ It is possible that such aspects introduced bias, but we believe that the balanced pragmatic approach taken to address the research questions was appropriate for this relatively small qualitative study. Interesting themes emerged in the analysis, and we were able to triangulate more factbased comments with documentary sources in the literature.

First a summary of key findings is presented (in the context of historical development of UAT in different countries, as well as what is already known of the subject), followed by a discussion on how the findings from this paper fit into broader contemporary debates about public health ethics and policy.

\section{Summary of key findings from interviews (in the context of what is currently known)}

In the UK, a balance of epidemiological and ethical considerations in the late 1980s led to the implementation of the 'prior notification' approach to UAT; this involves leaflets and posters informing clients that UAT is occurring, allowing opting out but not necessitating the gaining of informed consent. ${ }^{7}{ }^{10}$ Respondents stressed that the rationale remains apt today, and that this approach provides data unrivalled in terms of epidemiological quality, ${ }^{9} 2122$ and which is of use for health service planning. ${ }^{23}$ Ethical concerns were generally felt to be minimal today since clients are (also) usually offered voluntary (named) testing in settings where UAT is occurring. However, there was mention of concern about the lack of full explanation, whether people do actually know UAT is happening, and 'ownership' of blood. ${ }^{24}$ It was indicated that an approach involving informed consent would be cumbersome, timeconsuming and epidemiologically damaging. ${ }^{25}$

In the USA, UAT of blood for HIV was extensively used in the 1980s and early $1990 \mathrm{~s},{ }^{26}$ but was stopped in the late 1990s as evidence emerged that antiviral therapy in pregnant women could help reduce the vertical transmission of HIV from pregnant mother to child-named testing needed to be maximised so that HIV-positive pregnant women could be identified and offered advice and therapy. ${ }^{27}$ The interviews indicated that data from UAT were useful epidemiologically but, since UAT has stopped, there have been sufficient other data to plan services accordingly. Other issues raised include a general suspicion around epidemiological surveillance post-Tuskegee, cultural dimensions of UAT with respect to minority groups, a lack of trust in the Government, and the related disconnect between surveillance (done to all) and healthcare provision (variable, and not done to all). ${ }^{6} 11$ There was also comment about the apparent contradiction in the contemporary support of the US Centre for Communicable Disease Control and Prevention (CDC) for UAT in low-income countries. ${ }^{28}$

Interviews in the Netherlands showed that named (voluntary) testing, which has generally been widely taken up, has provided the main vehicle for surveillance of HIV. ${ }^{4}$ There is acknowledgement that large-scale UAT would provide additional epidemiological data, but this has been balanced against concerns of this leading to diminished voluntary testing-especially in at risk groups-through loss of trust in the healthcare system. ${ }^{29}$ Smaller UAT surveys have been intermittently undertaken in such groups (eg, IDUs, sex workers and migrants) as research studies, but have required individual consent (initially oral, now written).

Interviews in Norway revealed that UAT was never felt to be necessary epidemiologically, as HIV has not been a significant issue and the uptake of voluntary testing has been high. ${ }^{13}$ Surveillance has thus tended to focus on the monitoring of the diagnosed population (anonymised diagnosed cases), which has been supported by the gay community; the undiagnosed population is interestingly referred to as 'dark figure(s)'. In Norway it is not legal to test without consent unless there is an epidemic, although respondents reported few ethical concerns since people generally have trust in the healthcare system, and are willing to provide information for public health purposes (many give blood to the Biobank for a range of research purposes). ${ }^{30}$

The findings of this research on the ethics of UAT of blood need consideration in the context of two broader contemporary debates within medical and public health ethics. The first debate centres on the boundaries of informed consent in health research, particularly in relation to the use of human tissue. The second debate focuses on the balance between individuals' rights and 
the appropriate role of government in infringing on those rights for broader public health interests or concerns. These debates are inter-connected, although will be presented in turn.

\section{Informed consent and ethics: a changing debate}

Respect for autonomy is the bioethical principle that is most likely to be jeopardised by a programme of unlinked anonymous blood testing, since informed consent is not usually deemed necessary for an individual's blood to be included; this has tended to be the basis for opposition to UAT. ${ }^{51}$ The findings from our research show, however, that such positions differ between countries, and have also changed with time.

Debates in the late 1980s and early 1990s demonstrated the opposing views of those who were concerned about patient consent, ${ }^{8}{ }^{26}$ and those who felt that the priority was to control what was seen as an epidemic. ${ }^{15}$ UAT programmes did go ahead in the USA and the UK, and other high-income countries: there was no requirement for consent in the USA, whereas in the UK an approach of 'prior notification' was adopted through leaflets and posters in clinics-consent is presumed but individuals have the opportunity to opt-out.

Over the past two decades informed consent has emerged as 'the ethical touchstone of medical research, and is now enshrined in practice and a range of international guidelines as one of the main preconditions of medical research'. ${ }^{25}{ }^{32}$ Some commentators argue that even anonymised tissue should not be used without consent. Trouet, for example, believes that the use of such material is in contravention of Article 22 of the Convention on Human Rights and Biomedicine. This states that "when in the course of an intervention any part of a human body is removed, it may be stored and used for a purpose other than that for which it was removed, only if this is done in conformity with appropriate information and consent procedures', and in accordance with Article 8 of the European Convention on Human Rights which protects the right to respect for private life. ${ }^{33}$

Our research indicates that, rather than the universality of human rights discourse, a form of weak moral relativism operates in policy-making and practice around UAT. $^{34}$ In the USA, the change in social context and debates about individual rights, along with evidence of reduction in mother-to-child vertical transmission, resulted in the abandonment of UAT in $1996 .{ }^{12}$ The fact that the USA continued to support UAT in international research overseas illustrates further an attitude of moral relativism, although it could be argued that differential health needs justified different approaches.

Interviews in the UK showed that the prior notification approach that remains in use today still holds strong support-based on perception that there is minimal harm to the individual, and the value of high quality, unbiased epidemiological data on HIV (held to be the most robust and accurate worldwide). ${ }^{35}$
Respondents felt that any change to UAT requiring informed consent would be cumbersome, time consuming and costly. According to the Nuffield Council on Bioethics it may also be ethically unnecessary: “...it is acceptable to collect and use anonymised data for assessing and predicting trends in infectious disease without consent, as long as any invasion of privacy is reduced as far as possible." 36

This position is not, however, cross-culturally held. In the Netherlands, UAT has not been felt to be acceptable without informed consent, initially verbal and more recently written. The societal emphasis on individual autonomy, including in the health research environment, has been the paramount consideration. ${ }^{5}$ Northern European and Scandinavian countries are often held up as having a strong community ethos, with an expectation on individual involvement in endeavours for the public good. ${ }^{37}$ This was not reflected in UAT practice in the Netherlands, although was indicated to be important in Norway, albeit in a setting where UAT has never been taken up.

These findings indicate the importance of social and political context in relation to medico-ethical debates, and how attitudes and policies can change in time within any given jurisdiction. ${ }^{38}$ Differences exist between the moral evaluations and resultant UAT approaches between countries such as England and the Netherlands. Within the USA, in contrast, the practice of UAT has been re-evaluated with time. In the late 1980s and early 1990s the feared AIDS epidemic was seen as a public health emergency, there was no treatment available, transmission from mother to unborn child was not preventable and the stigma and discrimination associated with the infection were more overt than today. As these factors shifted, so did the policy on UAT in the USA. The situation in low-income countries today has created a perception of the acceptability of UAT akin to that in western countries two decades ago.

\section{Individual good and community (public) good}

There has been criticism in recent times of government for its 'nanny state' approach to interventions in, for example, the areas of smoking, alcohol and diet. Recently the notion of 'stewardship' in public health rejects these negative associations, ${ }^{39}$ and advocates that government should have a role to play in protecting the health of its citizens, preventing them from harming themselves or others and promoting healthy behaviour. ${ }^{\text {iv }}$ In this view, public health interventions should not be thought of as unwanted restrictions imposed by a 'nanny' on powerless children, but as actions that favour both individuals and society more widely as prescribed by a 'steward' administering and protecting citizens' interests. The Nuffield Council on Bioethics, for

${ }^{\text {iv }}$ By government, the meaning here is health and public health policy makers within government. 
example, argues that the state should act as steward both to individuals and to the population as a whole, but that individuals' personal choices should also be taken into account. $^{36}$

The subject of UAT sits squarely within the debate about public health stewardship for social good. Recently, commentators have argued that patients of a publicly supported healthcare system like the NHS have a moral duty to participate in scientific research, ${ }^{40} 41$ although most do not go so far as to articulate that such participation should be mandatory in practice. $^{42}$ Nevertheless, UAT could be understood as something that individuals should feel that they have a moral obligation to participate in, regardless of ethical concerns about individual rights and personally held views. Our own survey of over 400 users of two GUM clinics (a parallel part of this research project) has found that a large majority of respondents $(89 \%)$ agree that people should have a responsibility to take part in research studies, and the same proportion would agree to the use of their blood in unlinked anonymous seroprevalence testing. However, when asked about the question of consent, $74 \%$ indicated that they should be asked to consent before their blood is used for public health surveillance. ${ }^{14}$ Notwithstanding this important latter point, such support for use of blood samples for prevalence surveys or for future research has not, however, been demonstrated in an earlier study in the $\mathrm{UK}^{43}$ or recently in Egypt. ${ }^{44}$

The way forward perhaps is to ensure that patientsand the public more widely-are informed of the existence, purposes and value of disease surveillance arrangements, as well as the importance of contributing to future health research, while investigating arrangements for gaining consent which are not unnecessarily cumbersome or likely to create bias among those who agree that their blood be used. ${ }^{45}$

The issue of consent in seroprevalence surveillance, such as UAT, remains an important instrument to gauge the moral direction of public health policies more broadly. ${ }^{46}$ Debate continues around how public health programmes can embrace a stewardship relationship, rather than a nanny paternalistic one, while respecting autonomy and advocating social responsibilities. Further examination of why different countries have adopted different positions on seroprevalence surveillance will help illuminate our understanding of how social morality is embedded in public health policies and practice.

Acknowledgements The authors would like to thank the participants in the study. They also acknowledge the valuable advice given by Vivian Hope, Will Nutland, Cicely Marston and Graham Hart.

Contributors AK was the study principal investigator and was involved in conception of the idea, design of the study, analysis and interpretation of data and was lead author in drafting of the paper. JD was involved in conception of the idea and design of the study, led on analysis and interpretation of data and was involved in revising of the article critically and final approval of the version to be published. KW was involved in conception of the idea and design of the study, analysis and interpretation of data, revising of the article critically and final approval of the version to be published. SP was involved in analysis and interpretation of data, revising of the article critically and final approval of the version to be published.

Funding This research was supported by the Economic and Social Research Council (ESRC Grant Reference: RES-000-22-2096).

Competing interests AK is the Director of Public Health Strategy and Medical Director of the Health Protection Agency. The views expressed in this paper are those of the authors, and are not intended to represent the views of the Health Protection Agency.

Ethics approval The study was approved by the South West Research Ethics Committee on 16 August 2007 (reference 07/H0206/46), and by the London School of Hygiene and Tropical Medicine ethics committee on 3 September 2007 (reference 5174).

Provenance and peer review Not commissioned; externally peer reviewed.

Data sharing statement No additional data are available.

\section{REFERENCES}

1. Nicoll A, Gill ON, Peckham C, et al. The public health applications of unlinked anonymous seroprevalence monitoring of HIV in the UK. Int $J$ Epidemiol 2000;29:1-10.

2. Department of Health. Prevalence of HIV in England and Wales in 1997: annual report of the unlinked anonymous prevalence monitoring programme. London: Department of Health, 1998.

3. UK Collaborative Group for HIV and STI Surveillance. Testing times: HIV and other sexually transmitted infections in the UK. London: Health Protection Agency, 2007.

4. Bayer R, Lumey LH, Wan L. The American, British and Dutch responses to unlinked anonymous HIV seroprevalence studies: an international comparison. AIDS 1990;4:283-90.

5. Kopelman LM. Informed consent and anonymous tissue samples: the case of HIV seroprevalence studies. J Med Philos 1994;19:525-52.

6. Fairchild AL, Bayer R. Ethics and the conduct of public health surveillance. Science 2004;303:631-2.

7. Gill ON, Adler MW, Day NE. Monitoring the prevalence of HIV: foundations for a programme of unlinked anonymous testing in England and Wales. BMJ 1989;299:1295-7.

8. Berridge V. AIDS in the UK: the making of policy 1981-1994. Oxford: Oxford University Press, 1996.

9. Health Protection Agency. Overall HIV prevalence. Health Protection Agency. 2008. http://www.hpa.org.uk/web/HPAweb\&Page\& HPAwebAutoListName/Page/1201094588821

10. Gillon R. Testing for HIV without permission. BMJ 1987;294:821-3.

11. Fairchild AL, Bayer R, Colgrove J. Searching eyes: privacy, the state, and disease surveillance in America. Berkeley, CA: University of California Press, 2007.

12. Stoto MA, Almario DA, McCormick MC. Reducing the odds: preventing perinatal transmission of HIV in the USA. Washington: National Academy Press, 1999.

13. Aavitsland $P$, Nilsen $\varnothing$, Lystad A. Anonymous reporting of HIV infection: an evaluation of the HIV/AIDS surveillance system in Norway 1983-2000. Eur J Epidemiol 2001;17:479-89.

14. Datta J, Kessel AS, Wellings $\mathrm{K}$, et al. The views of genitourinary medicine (GUM) clinic users on unlinked anonymous testing of blood for HIV: evidence from a pilot study of clinics in two English cities. J Med Ethics 2011; doi:10.1136/jme.2011.042705

15. Doll R. A proposal for doing prevalence studies of AIDS. BMJ 1987;294:443-4.

16. Avins AL, Lo B. To tell or not to tell: the ethical dilemmas of HIV test notification in epidemiologic research. Am J Public Health 1989;79/ 11:1544-7.

17. Datta J, Kessel AS. Unlinked anonymous testing for blood purposes: an ethical dilemma? In: Peckham S, Hann A, eds. Public health ethics and practice. Bristol: Policy Press, 2010:101-16.

18. Bowling A. Research methods in health. Buckingham: Open University Press, 2000.

19. Yin RK. Case study research: design and methods. London: Sage, 1994.

20. Green J, Thorogood N. Qualitative methods for health research. London: Sage, 2004.

21. Duong T, Ades AE, Rogers $P$, et al. Non-participation bias in unlinked anonymous HIV-prevalence surveys in England and Wales. Epidemiol Infect 1999;122:267-72. 
22. Pulver WP, Glebatis D, Wade N, et al. Trends from an HIV seroprevalence study among childbearing women in New York State from 1988 through 2000: a valuable epidemiologic tool. Arch Pediatr Adolesc Med 2004;158:443-8.

23. Kessel AS, Watts CJ. Usefulness of information from the unlinked anonymous prevalence monitoring programme for HIV in England and Wales: survey of planners of HIV/AIDS services. Int J STD AIDS 1999;10:808-11.

24. Pfeffer N, Laws S. 'It's only a blood test': what people know and think about venepuncture and blood. Soc Sci Med 2006;62:3011-23.

25. Cassell J, Young A. Why we should not seek individual informed consent for participation in health services research. J Med Ethics 2002;23:313-17.

26. Bayer R. The ethics of blinded HIV surveillance testing. Am J Public Health 1993;83/4:496-7.

27. de Zulueta P. The ethics of anonymised HIV testing of pregnant women: a reappraisal. J Med Ethics 2000;26:16-21.

28. Rennie S, Norris Turner A, Mupenda B, et al. Conducting unlinked anonymous HIV surveillance in developing countries: ethical, epidemiological, and public health concerns. PLoS Med 2009;6: e1000004.

29. Postema EJ, Willems PWJM, de Ridder MAJ, et al. Comparison of patients refusing with patients accepting unlinked anonymous HIV testing in an outpatient STD department in the Netherlands. Int J STD AIDS 1997;8:368-72.

30. Skolbekken J-A, Ursin LO, Solberg B, et al. Not worth the paper it's written on? Informed consent and Biobank research in a Norwegian context. Crit Public Health 2005;15:335-47.

31. Beauchamp TL, Childress JF. Principles of biomedical ethics. New York: Oxford University Press, 1994.

32. Singleton $P$, Wadsworth $M$. Consent for the use of personal medical data in research. BMJ 2006;333:255-8.
33. Trouet C. New European guidelines for the use of stored human biological materials in biomedical research. J Med Ethics 2004;30:99-103.

34. Rachels J. The elements of moral philosophy. New York: McGraw-Hill, 1993.

35. Beuhler JW, Petersen LR, Ward JW, et al. Defending HIV seroprevalence surveys. Am J Public Health 1994;84:319-20.

36. Nuffield Council on Bioethics. Public health: ethical issues. London: Nuffield Council on Bioethics, 2007.

37. Cappelen AW, Norheim OF. Responsibility in health care: a liberal egalitarian approach. J Med Ethics 2005;31:476-80.

38. Mariner WK. Mission creep: public health surveillance and medical privacy. Boston Univ Law Rev 2007;87/2:347-95.

39. Jochelson K. Nanny or Steward? The role of government in public health. King's Fund Working Paper. London: King's Fund, 2005.

40. Harris J. Scientific research is a moral duty. J Med Ethics 2005;31:242-8

41. Evans HM. Do patients have duties? J Med Ethics 2007;33:689-94.

42. Shapshay S, Pimple KD. Participation in biomedical research is an imperfect moral duty: a response to John Harris. J Med Ethics 2007;33:414-17.

43. Kessel AS, Watts C, Weiss HA. Bad blood? Survey of public's views on unlinked anonymous testing of blood for HIV and other diseases. BMJ 2000;320:90-1.

44. Abou-Zeid A, Silverman $\mathrm{H}$, Shehata $\mathrm{M}$, et al. Collection, storage and use of blood samples for future research: views of Egyptian patients expressed in a cross-sectional survey. J Med Ethics 2010;36:539-47.

45. Nicholls SG. Knowledge or understanding? Informed choice in the context of newborn bloodspot screening. Public Health Ethics 2010;3:128-36.

46. Haimes $\mathrm{E}$. What can the social sciences contribute to the study of ethics? Theoretical, empirical and substantive considerations. Bioethics 2002;16/2:89-113. 